\title{
Unresectable Chordoma
}

National Cancer Institute

\section{Source}

National Cancer Institute. Unresectable Chordoma. NCI Thesaurus. Code C153325.

A chordoma which is not amenable to surgical resection. 